\title{
LA FUERZA VINCULANTE DE LAS SENTENCIAS CONSTITUCIONALES Y EL RECONOCIMIENTO DE DERECHOS FUNDAMENTALES. A PROPÓSITO DE LA LEY SOBRE REGULACIÓN DE LA FERTILIDAD
}

\author{
THE BINDING FORCE OF THE CONSTITUTIONAL RULINGS AND \\ THE RECOGNITION OF FUNDAMENTAL RIGHTS. ON PURPOSE OF \\ THE BILL ABOUT FERTILITY REGULATION
}

\author{
Gonzalo Carreño PaVez \\ JORGE JARAQUEMADA ROBLERO*
}

\begin{abstract}
RESUMEN: Se discute el impacto de las decisiones del Tribunal Constitucional, en su rol de supremo intérprete de la Constitución, sobre los demás poderes del Estado, particularmente sobre el Gobierno y el Congreso, en especial cuando sus sentencias versan sobre el sentido y alcance de derechos fundamentales. Se plantea que los precedentes que sientan ese tipo de sentencias no pueden ser desconocidos en la medida que los derechos fundamentales son una barrera infranqueable para los poderes colegisladores.
\end{abstract}

Palabras clave: precedente, interpretación constitucional, derechos fundamentales.

ABSTRACT: The authors discuss the impact of the Constitutional Court decisions, in its role as the supreme interpreter of the Constitution, on the other branches of government, particularly the government itself and the Congress, especially when its sentences are about the meaning and scope of fundamental rights, such as the right to life of the unborn. Besides, they sustain that the precedents that this kind of sentences stand, can't be ignored neither by the Constitutional Court itself nor by the government entities in their future decisions, insofar the fundamental rights are an unbridgeable barrier for the colegislative branches.

Key words: precedent, constitutional interpretation, fundamental rights.

\section{INTRODUCCIÓN}

La justicia constitucional es hoy, ante todo, una justicia de los derechos fundamenta-

\footnotetext{
* Abogado. Licenciado en Ciencias Jurídicas por la Pontificia Universidad Católica de Chile. Jefe de Gabinete del Ministro de Energía. Fue investigador del Área Legislativa de la Fundación Jaime Guzmán. Dirección: Alameda 1449, piso 14, Santiago. Fono: 09-1397491. Correo electrónico: gonzalocarren@gmail.com
}

les ${ }^{1}$, principalmente por la obligación positiva y directa de respeto que reclaman sus enunciados jurídicos que -como tantas veces se ha repetido- solo se limitan a reconocer derechos y

\footnotetext{
** Abogado. Licenciado en Ciencias Jurídicas por la Pontificia Universidad Católica de Chile. Magíster en Ciencia Política por la Universidad de Chile. Director Ejecutivo de la Fundación Jaime Guzmán. Dirección: Capullo 2240, Providencia. Fono: 9401100. Correo electrónico: jjaraquemada@fjguzman.cl ${ }^{1}$ Para una conceptualización sobre derechos fundamentales véase CEA (2002) p. 221.
} 
no son producto de la voluntad mayoritaria del legislador o de la soberanía nacional, y también por la creciente tensión que se produce entre los órganos estatales y los individuos producto de la tendencia hacia la expansión que permanentemente reclaman los derechos esenciales. Como lo afirma Alexy, la dogmática de estos derechos se construye principalmente en el ámbito de la jurisprudencia constitucional, pues "si la discusión acerca de los derechos fundamentales no pudiera apoyarse más que en el texto de la Constitución y en el terreno movedizo de su génesis, habría que contar con un casi interminable e ilimitado debate de opiniones" 2 . Es por ello que en esta materia, más que en ninguna otra, es tan relevante el papel que juegan tanto el precedente como la cosa juzgada constitucionales.

El fallo sobre la llamada 'píldora del día después', pronunciado en Sentencia rol No 740, de 18 de abril de 2008, por el cual el Tribunal Constitucional chileno declaró la inconstitucionalidad de parte del Decreto Supremo No 48, del Ministerio de Salud, de 3 de febrero de 2007, que aprobó las "Normas $\mathrm{Na}$ cionales sobre Regulación de la Fertilidad", ha revivido sensibles puntos en la discusión jurídica de la doctrina constitucional. Dicha Magistratura, siendo fiel a los valores y principios $^{3}$ implícitos en nuestra Constitución, entregó las pautas esenciales para una justa inteligencia del contenido del derecho a la vida consagrado en su artículo 19 número $1^{\circ}$ y la titularidad cabal del mismo al que está por nacer, el nasciturus. Sin embargo, un análisis detenido de la Sentencia no puede contentarse solo con el examen material de los fundamentos contenidos en esa exégesis de la Carta Magna, por profundos y relevantes que estos puedan ser, antes bien, debe detenerse en las consecuencias -externas o adyacentes- al caso particular objeto de dicha interpretación.

Permítasenos poner nuestros planteamientos en términos interrogativos: ¿qué es lo

\footnotetext{
2 Alexy (2002) p. 23.

3 Sobre la distinción entre valores y principios: Díaz REVOrio (1997) y Freixes y REMOTTI (1992). Para una postura crítica: Aldunate (1993) y ALCALDE (2008).
}

que realizó el Tribunal Constitucional al interpretar la mencionada disposición constitucional en esa sentencia?, ¿cómo se incorpora dicha interpretación al texto constitucional?, ¿cuál es el grado de fijeza del que debe gozar ese criterio hermenéutico? y ¿a quiénes obliga? En estas interrogantes no solo se involucran asuntos de derecho sustantivo, que difícilmente pueden darse todos por resueltos a través de la vía constitucional, sino que también se mezclan problemas de derecho adjetivo que, atendidas las peculiaridades de la justicia constitucional ${ }^{4}$, pueden resultar tan espinosos como los primeros. En particular, para nuestro análisis resultan relevantes la cosa juzgada material o sustancial de la sentencia constitucional y la técnica de los precedentes que ha adoptado la Magistratura Constitucional chilena desde $1993^{5}$. Por cierto, antes deberemos pasar breve revista a la cuestión primordial que cruza el constitucionalismo contemporáneo: la interpretación constitucional. Y es que desde que ha sido asumido por nuestra tradición jurídica que la Constitución es una norma jurídica propiamente tal, obligatoria, justiciable y autoejecutiva, y no un mero código de carácter eminentemente político, no puede menos que reconocerse el relieve que la necesaria interpretación de la norma constitucional adquiere en el contexto de la realización de sus enunciados. No por nada ha señalado Rubio Llorente que la teoría de la interpretación es el núcleo central de la Teoría de la Constitución ${ }^{6}$. Revisemos sucintamente este tema antes de entrar propiamente en la materia que nos convoca.

\section{NOTAS SOBRE LA INTERPRETACIÓN CONSTITUCIONAL}

La misión del intérprete constitucional resulta irresistiblemente creadora y va mucho

\footnotetext{
4 "Los efectos erga omnes que se atribuyen a las sentencias recaidas en los procesos de inconstitucionalidad, ponen de manifiesto, prima facie, la imposibilidad de aplicar a este tipo de sentencias los principios procesales comunes respecto de los efectos de las sentencias" (COLOMBO, 2002a, p. 66).

5 Véase Sentencia rol N¹71 de 1993 del Tribunal Constitucional chileno.

${ }^{6}$ Rubio Llorente (1993) pp. 605 y ss.
} 
más lejos de su función tradicional de ser un traductor fiel del tenor literal de la ley ${ }^{7}$. La interpretación es la producción del sentido del texto constitucional ${ }^{8}$ : la producción del sentido es la norma y el texto sobre el que se produce es el enunciado normativo, la disposición. En toda interpretación hay una actividad creadora de derecho, ya que el exégeta jurídico imputa un significado a la disposición que es objeto de la actividad hermenéutica, entre diversos significados posibles 9 . Aun cuando el Tribunal Constitucional no es el único autorizado a interpretar la Carta Fundamental, sí es su intérprete final. En efecto, si bien no goza del monopolio interpretativo, es claro que dicha labor corresponde primariamente al órgano de jurisdicción constitucional y que en el ejercicio de tal facultad este 'crea' derecho -aunque, por cierto, no legisla- de manera tal que el contenido de sus sentencias debe considerarse la guía suprema en las materias abordadas respecto de todos los demás tribunales. Si para ello debe echar mano, como creemos que corresponde, de los elementos axiológicos o teleológicos que se desprenden de la preceptiva constitucional, ello no se debe más que a las peculiares características de la interpretación constitucional, para la cual, como se suele reiterar por los constitucionalistas, no bastan las tradicionales reglas hermenéuticas iusprivatistas trazadas por Savigny.

La interpretación, así lo ha señalado repetidamente el Tribunal Constitucional ${ }^{10}$,

7 Colombo (2002b) p. 548. Este carácter creativo dista mucho de ser una cuestión pacífica, sin embargo, como apunta Díaz REVORIO (1997) p. 326, en materia constitucional es más sencillo encontrar opiniones que sustenten este aserto. La filosofía jurídica ha desarrollado latamente las dificultades teóricas y filosóficas que se ven envueltas en la problemática de la interpretación jurídica. De hecho, la historia del pensamiento filosófico-jurídico moderno puede leerse como un continuo en cuyo centro se encuentra la cuestión dogmática de la interpretación del derecho. En este sentido: PRIETO SANCHÍs (1987)

8 PICA (2006) p. 151.

${ }^{9}$ Nogueira (2006a) p. 151.

10 Así por ejemplo, véase el Considerando Sexto de la Sentencia rol No 325 de 2001 del Tribunal Constitucional chileno. debe tener presente aquellos elementos axiológicos que se desprenden de la Carta Fundamental para una adecuada inteligencia de lo que se expresa en ella. Con notable agudeza indica Cea: "En la Ley Suprema, los valores son innumerables y correcto sería aseverar que no hay precepto alguno de ella que no exprese un valor, no lo asuma, esté implícito en ella o, por último, no sea posible derivarlo de su contexto, del alma de la Constitución (...) si todas y cada una de sus normas cristalizan o albergan valores, también ha de ser desentrañado su sentido y alcance para aplicarlas ciñéndose a los imperativos que ellas contienen"11.

El papel que juegan los elementos axiológicos en la interpretación constitucional también ha sido recogido ampliamente a nivel comparado, tanto por la doctrina como por la jurisprudencia constitucional latinoamericana, porque le aportan vitalidad al texto constitucional en cuanto colaboran a desentrañar y explicitar su verdadero sentido y espíritu. Desde la doctrina internacional nos enseña Bidart Campos con precisión: "Cuando una jurisdicción constitucional (...) cree que su función se reduce negativamente a descalificar las normas y los actos contrarios a la Constitución, y no asume que también le pertenece la de intérprete de la Constitución y la de creación judicial en todo el espectro de cuestiones que poseen materia y contenido constitucional (...) cuando ignora que su jurisprudencia sienta doctrina al fijar cuál es la interpretación constitucional admisible, la jurisdicción constitucional se repliega y se limita en un 'self restraint' [autocontrol] que no reputamos idóneo ni conducente" $^{12}$. Mientras que desde la jurisprudencia lo hace la Corte Suprema de Justicia de Colombia: "Si se quiere vivificar la Constitución, ello exige entender que ella no solo está conformada por las normas positivas en que se expresa, sino por lo principios implícitos en las mismas y por los valores enunciados como objetivo de su preceptiva; estas son instancias supra, aunque no extra constitucionales, a las cuales es necesario referir toda interpretación y explicación de las normas positivas, y su des-

11 CEA (1992) pp. 91-94.

12 BidART (1994) p. 133. 
conocimiento debe acarrear invalidez, inconstitucionalidad, pues todo lo que sea contrario al derecho, y a un control de constitucionalidad que no tenga este enfoque es incompleto y carece de eficacia"13.

De lo anterior se colige que la labor del intérprete, aunque eminentemente creadora, no es libre y no incorpora nada a la norma constitucional que no haya estado comprendida en ella, al menos en carácter de potencia. Es decir, no incorpora un producto extraído ex nihilo. El rol del intérprete consiste en extraer del enunciado constitucional aquello ya presente en el mismo, aun bajo las nociones de valores o principios, que pueden ser todo lo imprecisos que se quiera, pero no por ello menos palpables, para ampliar o restringir sus alcances a aspectos no contemplados con anterioridad, e incluso para extenderse a horizontes no previstos por el constituyente original. La tarea del exégeta, en fin, es extraer del texto su 'voluntad objetiva', empeño que en el peculiar campo constitucional puede llegar a transformarse en una actividad creadora o atributiva incluso en mayor medida que extractiva o descubridora, pues no serán pocas las ocasiones en que dicha voluntad simplemente no exista ${ }^{14}$. Evidentemente, esta tesis de creación interpretativa no puede llegar a los extremos de considerarse íntegramente como una nueva preceptiva adosada a la Carta Fundamental, pues ello implicaría la asfixia de la textura abierta. Es una característica que debe considerarse constitutiva de la interpretación, pues a la vez que posibilita la libertad del intérprete, también establece las guías que orientan el desempeño de esa libertad mediante una cierta clausura que no es otra que la llamada 'alma' de la Carta Magna. Aceptado lo anterior, la cuestión es dilucidar si la interpretación tiene el efecto de incorporar el producto del análisis hermenéutico -cuya estabilidad no está garantizada por norma alguna- en el enunciado normativo del precepto constitucional interpretado con las mismas notas de permanencia de las que gozan las normas

13 Véase la Sentencia rol No 51 de 1988, de la Corte Suprema de Justicia de Colombia.

${ }^{14}$ Rubio Llorente (1993) p. 619. constitucionales. Señalábamos que el intérprete -en especial el constitucional- crea derecho, y lo hace en razón de la peculiar índole de su disciplina, nutrida de particularidades que la hacen especialísima dentro de la dogmática jurídica.

\section{LA FUERZA DEL PRECEDENTE CONSTITUCIONAL}

El solo planteamiento de las consideraciones anteriores nos remite a la distinción que frecuentemente se plantea entre los sistemas concentrados de control de constitucionalidad y los sistemas difusos ${ }^{15}$, aunque cada vez es más evidente el proceso de fusión entre ambos esquemas, en especial a raíz de la incorporación del stare decisis como un efecto de la sentencia constitucional en ámbitos jurídicos de tradición europea. En este sentido, consideramos que la doctrina del precedente juega un rol indiscutible en la creación y desarrollo de una auténtica jurisprudencia constitucional ${ }^{16}$.

Los efectos de sus sentencias no se limitan a la mera determinación de inconstitucionalidad o constitucionalidad de una determinada norma concreta, muy por el contrario, están llamadas a tener significativa influencia en el comportamiento de todos los órganos del Estado. La doctrina habitualmente se hace cargo de los efectos que los fallos constitucionales deben tener sobre aquellos otros que dicte la justicia ordinaria, en el habitual efecto vertical característico del stare decisis, sin embargo, no debe minimizarse el efecto que esos pronunciamientos jurisdiccionales deben tener sobre todos los demás órganos del Estado, particularmente sobre los poderes colegisladores, en el contexto de un Estado Constitucional y Democrático de Derecho. La fuerza vinculante de las sentencias constitucionales que hemos planteado es lo que constituye el precedente constitucional. Pero no debe confundirse dicho carácter con la cosa juzgada de la que gozan estos fallos -que es la certeza declarada en la sentencia que impide una nueva decisión de

\footnotetext{
15 En este sentido, Ruiz Miguel (2000); PEÑA (2006); y GUASTINI (2008) p. 47.

16 ZAPATA (2008) pp. 359 y ss.
} 
fondo sobre el mismo litigio-; ni con los efectos que se derivan de la decisión adoptada en la parte resolutiva; ni tampoco con el efecto erga omnes propio de la declaración de inconstitucionalidad, que provoca la derogación o abrogación de la norma viciada, según el caso, y que obliga a toda persona, grupo y órgano del Estado; aunque ciertamente el precedente participa de la cosa juzgada de la que goza la parte resolutiva de la sentencia y también se beneficia del efecto erga omnes que se atribuye a los fallos que declaran una inconstitucionalidad.

Si el intérprete 'crea' derecho al pronunciarse sobre eventuales vicios sometidos al control de constitucionalidad de las normas emanadas de los legisladores, entonces el intérprete constitucional debe procurar en su tarea el máximo rigor posible y la mayor coherencia jurídica que pueda conservar en el tiempo, tanto respecto de los criterios aplicados a las soluciones concretas, como de las interpretaciones de la Constitución que realiza. De no ser así, podría sostenerse que de su arbitrio, aparte de confusión, estaría emanando mera voluntad política, esto es, estaría 'legislando' sin gozar de las atribuciones soberanas para hacerlo.

Dicho lo anterior, cabe precisar cuál es entonces el contenido del precedente constitucional. Valga al efecto apuntar la útil precisión que efectúa Nogueira: "La fuerza vinculante del precedente está relacionada con el tema de la decisión, lo que lleva a una utilización restrictiva y limitada del precedente, a los casos efectivamente análogos, como asimismo considerando como precedente solamente los principios y reglas contenidas en el holding o la ratio decidendi de la sentencia, no pudiendo extenderse a consideraciones periféricas contenidas en el fallo". La ratio decidendi entonces "es la parte del fallo que fundamenta directa e inmediatamente el precedente, estableciendo la regla o principio que define el tribunal al resolver el problema o caso sometido a su consideración" ${ }^{17}$, dejando fuera de ella todos los demás razonamientos accesorios o circunstanciales. En consecuencia, es únicamente la ratio

17 Nogueira (2006a) p. 169. decidendi o los criterios y razonamientos jurídicos centrales plasmados en una sentencia y que han sido el fundamento directo de lo que allí ha decidido una corte constitucional lo que posee valor vinculante como precedente para el propio tribunal en sus decisiones posteriores y, tal vez más importante aún, lo que se constituye en la doctrina que debe orientar las decisiones del resto de los órganos del Estado, puesto que ha surgido de la jurisprudencia de quien es el intérprete último de la normativa constitucional. Ha dicho Guastini: "La interpretación del tribunal constitucional, a su vez, no puede ser revertida por nadie. Una reforma constitucional, desde luego, puede revertir su decisión sobre la ilegitimidad constitucional, pero no su interpretación del texto constitucional: la reforma constitucional no consiste en cambiar la interpretación de la constitución, sino su texto"18.

Además, el precedente tiene un rol fundamental en el orden político y social en la medida que permite dar consistencia y previsibilidad a la interpretación del ordenamiento jurídico constitucional y cumplir con ciertos estándares de razonabilidad y universalidad en la aplicación de la preceptiva constitucional, con la consiguiente ganancia en términos de la certeza jurídica que se obtiene, de tal manera que al lado de la cosa juzgada habría también una muy útil 'cosa interpretada'.

Por supuesto que el respeto al precedente no significa, en ningún caso, una total sujeción a él por parte del Tribunal Constitucional o su absoluta inmutabilidad en el tiempo. Es legítimo apartarse de la doctrina asenta$\mathrm{da}$ por el precedente en una materia determinada si hay un razonamiento que justifique el cambio de criterio. El mismo Tribunal ha sostenido que "Los cambios de doctrina jurídica por lo general deben producirse siempre que existan motivos o razones fundamentales que los justifiquen"19. Y así también lo ha señalado Zapata: "La sujeción al precedente debe (...) constituir la regla general. Solo razones poderosas justificarían desechar una doc-

\footnotetext{
18 GUASTini (2008) p. 47.

19 Véase el Considerando $15^{\circ}$ de la Sentencia rol $N^{\circ}$ 171 de 1993 del Tribunal Constitucional chileno.
} 
trina previa. Para proceder a desestimar un precedente el TCCh [Tribunal Constitucional chileno] tendría que explicar las razones del giro y fundamentar adecuadamente su nueva interpretación" ${ }^{20}$. El mismo autor propone dos precisiones para justificar un cambio de doctrina jurisprudencial: la primera es que debe reconocerse una mayor estabilidad a las interpretaciones en materia de delimitación de potestades que a aquellas que versan sobre el sentido y alcance de los derechos fundamentales de la persona humana; la segunda es que solo se justificaría desestimar un precedente cuando este revela ser errado y además produce graves distorsiones o problemas para la aplicación del derecho ${ }^{21}$. Justifica la dualidad de tratamiento en el mayor rango constitucional que poseen los derechos fundamentales, de modo que allí donde la materia es más sensible menos razones hay para justificar la perseverancia en el error.

Aunque se coincide con estos criterios, nos parece relevante poner de relieve que la doctrina de los derechos humanos es una materia que dista de suscitar consenso en cuanto a sus fundamentos últimos -y también respecto a sus alcances concretos- abonándose en su terreno frecuentes polémicas en las que difícilmente puede aplicarse un criterio maniqueo de acierto o error. La jurisprudencia que emane de la Magistratura Constitucional deberá, por ende, estar siempre acompañada de fundamentaciones rigurosas y sólidas, virtudes difícilmente conciliables con la falta de estabilidad y permanencia. Por cierto, no cabe menospreciar el rol que juega la mantención de los criterios y razones jurídicas que fundan las decisiones de la justicia constitucional, en la certeza y seguridad jurídicas de todos aquellos a quienes les afectan o importan las materias resueltas en sus fallos y, en última medida, en la previsibilidad de los pronunciamientos judiciales que le incumben a la sociedad en su conjunto, particularmente cuando se refieren al contenido esencial o bien al alcance de los derechos humanos.

\footnotetext{
20 ZAPATA (2008) p. 371.

21 En la misma línea de este segundo criterio se muestra NOGUEIRA (2006b) p. 109.
}

En Chile, el propio Poder Ejecutivo ha reconocido los beneficios de este carácter vinculante para la estabilidad de las decisiones de los órganos públicos. En efecto, en el Mensaje que abre el proyecto de ley que modifica la Ley Orgánica Constitucional del Tribunal Constitucional, el entonces Presidente Ricardo Lagos Escobar, sostuvo: "Esta fuerza atribuida a las sentencias del Tribunal [Constitucional] permite, además, que el proyecto recoja una doctrina desarrollada por el propio Tribunal, en el sentido de quedar vinculado por sus precedentes, sin perjuicio de cambiar lo resuelto con anterioridad, por razones fundadas. Con ello se logra la necesaria estabilidad y certeza jurídica para las decisiones de los órganos del Estado, considerando que todos ellos quedan obligados por las sentencias del Tribunal [Constitucional]"22. A tal punto, agregamos nosotros, que hace parte de esa certeza jurídica exigir al intérprete, sea quien sea, que respete a toda costa el principio de supremacía constitucional y, por ende, los derechos fundamentales que ese principio salvaguarda.

\section{3. ¿ES POSIBLE UNA VUELTA ATRÁS EN MATERIA DE DERECHOS FUNDAMENTALES?}

Las consideraciones previas en torno a la fuerza vinculante de los precedentes para la propia magistratura constitucional que las dictó, en un efecto que podríamos denominar reflejo, pero también, y tal vez más significativamente, en su conexión y fuerza respecto de los demás órganos del Estado, nos remite a un cuestionamiento especialmente atingente a la materia que analizamos: ¿puede legítimamente una corte constitucional desestimar un precedente que establece una cierta interpretación acerca del contenido material de un derecho fundamental, para imponer, acto seguido, una interpretación restrictiva o simplemente abrogatoria del mismo? Resulta bastante evidente, a juicio nuestro, que un pronunciamiento her-

${ }^{22}$ Mensaje 432/353 del Presidente de la República por el cual inicia un proyecto de ley que modifica la Ley No 17.997, Orgánica Constitucional del Tribunal Constitucional (Boletín 4059-07) p. 10. 
menéutico de ese tenor, en sede de jurisdicción constitucional, por el solo hecho de emitirse, constituiría un atentado contra los derechos fundamentales y, por ende, una transgresión de lo prescrito por el artículo $5^{\circ}$, inciso segundo de nuestra Carta Fundamental. Es decir, una vez efectuado el reconocimiento de un derecho humano o fijados su sentido y alcance, sea que se haga por la vía normativa o jurisprudencial, simplemente ya no hay vuelta atrás. Esta doctrina es ampliamente conocida en materia de derechos humanos, recibe el nombre de 'principio de interdicción de regresión' o simplemente 'principio de no regresión' y se funda en el mero examen de los presupuestos requeridos para que un derecho pueda considerarse fundamental. En efecto, la doctrina en materia de derechos humanos enseña de manera unánime que ellos son anteriores a la legislación e inherentes a la persona humana y que a las legislaciones, tanto internacionales como domésticas, solo les cabe reconocerlos, enunciarlos, asegurarlos y garantizarlos.

No es el fomento de los derechos humanos ni la conveniencia práctica lo que funda esta prohibición de volver atrás, sino que son la congruencia y la lógica natural y jurídica las que impiden efectuar una regresión desde que se ha reconocido un derecho fundamental o se han fijado sus alcances y delimitado sus contornos. Al respecto ha señalado Nikken: "[u]na vez que un determinado derecho ha sido formalmente reconocido como inherente a la persona humana queda definitiva e irrevocablemente integrado a la categoría de aquellos derechos cuya inviolabilidad debe ser respetada y garantizada. La dignidad humana no admite relativismos, de modo que sería inconcebible que lo que hoy se reconoce como un atributo inherente a la persona, mañana pudiera dejar de serlo por una decisión gubernamental" 23 . De este carácter de atributo inherente se deriva que "la irreversibilidad es una característica fundamental de los derechos humanos, que consiste en la imposibilidad de desconocer la condición de un derecho como inherente a la persona humana, una vez que el Estado lo ha reconocido a través de

${ }^{23}$ NIKKEN (1994) p. 24. su propio texto o de un tratado internacional, ya que los derechos son inherentes a la dignidad de la persona humana y el texto constitucional solo los asegura y garantiza" 24 . En consecuencia, respecto de los derechos esenciales solo cabe la progresión, en ningún caso la regresión, permitirla constituiría en sí mismo una violación flagrante del derecho ya reconocido y desmoronaría el andamiaje jurídico completo sobre el que se sustenta la dogmática de los derechos humanos. No parece desmesurado, entonces, plantear que aun cuando un derecho esencial fuera eliminado del catálogo de derechos reconocidos y asegurados formalmente por la Constitución, este seguiría obligando igualmente a los órganos del Estado en carácter de derecho implícito.

Desde la doctrina latinoamericana más conspicua, Bidart Campos nos ilustra: "Una primera limitación que juzgamos nociva y reduccionista del rol de la jurisdicción constitucional la hallamos en la creencia -que nos atrevemos a denominar supersticiosa- que proviene de suponer que un sistema de derechos humanos requiere inexorablemente, para su reconocimiento, su funcionamiento y su tutela, constar siempre en normas escritas, de forma que si la norma falta o no existe, la carencia o el vacío significan la recíproca ausencia del derecho omitido en la normatividad. Constituciones que contienen una norma sobre derechos implícitos están llamándonos la atención sobre lo inadecuado y erróneo -a la par que injusto- de la limitación que apareja una interpretación de aquel tipo, porque dan hospedaje benévolo a derechos no enumerados cuya fuente -para decirlo en una sola palabraradica en el sistema democrático (...)"25. Una opinión similar respecto al valor implícito de los derechos fundamentales en nuestro ordenamiento jurídico constitucional, en cuanto se alzan como límite a la soberanía incluso para el poder constituyente, y con el mérito de haberlo aseverado con décadas de anticipación, expresó Jaime Guzmán en las sesiones de la Comisión de Estudios para una Nueva Constitución, a propósito de la discusión sobre el

24 Nogueira (2006a) p. 275.

25 BIDART (1994) p. 131. 
artículo $5^{\circ}$ inciso $2^{\circ}$ de la Constitución, señalando: "ese texto autoriza a entablar incluso recursos de inaplicabilidad y a pedir la inconstitucionalidad de leyes que aunque no violenten algún texto expreso de la Constitución, violenten derechos fundamentales de la persona humana, porque al hacerlo están violentando el texto expreso de la Constitución: el que señala que la soberanía está limitada por los derechos fundamentales o naturales del hombre" 26 .

En consecuencia, atendido lo señalado por el artículo $5^{\circ}$, inciso $2^{\circ}$ de nuestra Carta Fundamental, una reforma legislativa, cualquiera sea su rango, que tenga por efecto, de manera directa o indirecta, la eliminación o degradación de esos derechos esenciales, es una reforma que carece de total validez jurídica, pues no está permitido al constituyente derivado socavar la estructura material de nuestro Estado Constitucional y Democrático de Derecho que, en último término, radica y se edifica en el respeto de la dignidad de la persona humana, encontrando en ella su fundamento y su legitimidad.

Bien podría decirse que el respeto a los derechos esenciales reconocidos por el Código Político, en consecuencia, se levanta como una barrera infranqueable frente a la voluntad del constituyente, de forma tal que, además de los límites formales y de procedimiento que la propia Constitución le impone, y ciertamente muchísimo más importante que ellos, el reformador constitucional encuentra en los derechos esenciales un óbice de carácter sustantivo que, al mismo tiempo que le exige su constante afirmación (artículo $1^{\circ}$ inciso 4 ), también le prohíbe conculcarlos, degradarlos y menos derogarlos (artículo $5^{\circ}$ inciso 2). Ello, por lo demás, es lógico si se atiende a que el contenido esencial de los derechos fundamentales es una realidad previa a su reconocimiento constitucional y que los ordenamientos jurídicos de los Estados Constitucionales y Democráticos de Derecho, luego de reconocer estos atributos esenciales de la persona, suelen establecer una

26 Actas oficiales de la Comisión de Estudio de la Nueva Constitución Política de la República: sesión $101^{\mathrm{a}}$, de 9 de enero de 1975 . prohibición al legislador para que, en su legítimo afán de regularlos o de restringirlos, no afecte la esencia de estos derechos ni tampoco les imponga condicionamientos que impidan su libre ejercicio, cuestión que en nuestro ordenamiento constitucional está expresamente recogida en el artículo 19 No 26. Por cierto que la configuración de la esencia de un derecho está implícita en el enunciado normativo de la Constitución o Tratado que lo reconoce, pero la explicitación de sus contornos tiene que estar entregada a los tribunales, particularmente a la magistratura constitucional en el caso de los derechos fundamentales, pero no así al legislador, pues si la labor de determinar qué es lo esencial y qué es lo marginal en un derecho se confiara a este -que es el primer interesado en regular los derechos, potestad que tiene la obvia consecuencia potencial de afectarlos-, entonces el límite impuesto al ejercicio de la soberanía en la Constitución sería efímero, ya que la discrecionalidad legislativa podría determinar que es marginal aquello que en verdad es esencia de un derecho y, por esta vía, legitimar su potestad de afectación.

En el sistema internacional de derechos humanos existe una notoria unanimidad respecto a este predicamento. Como ha señalado Cervati: "existe un núcleo de principios inderogables incluso para las mayorías que pudieran reformar la Constitución. Este núcleo inviolable comprendería tanto los principios fundamentales del ordenamiento constitucional como los derechos inalienables de la persona humana" ${ }^{27}$. Así también lo ha sostenido la doctrina nacional: "La dignidad del ser humano es el mínimum invulnerable que todo ordenamiento y operador jurídico debe asegurar y garantizar, sin que nunca pueda legitimarse un menosprecio del ser humano como persona digna (...) La afirmación constitucional de la dignidad humana constituye un enunciado constitucional de eficacia directa y de aplicabilidad inmediata, teniendo un efecto anulatorio o invalidatorio de toda norma que contravenga o ignore dicha dignidad" 28 o ciertamente,

\footnotetext{
27 Cervati (1991) p. 55.

${ }^{28}$ Nogueira (2006a) p. 225.
} 
agregamos nosotros, los derechos emanados de ella.

Si, como señalábamos, en materia de derechos fundamentales la revocabilidad de la interpretación se topa con el obstáculo insalvable de la naturaleza específica, no ya de la interpretación constitucional, sino de la doctrina de la inherencia de los derechos humanos, haciendo inconcebible la reversibilidad de su reconocimiento en cuanto derechos, y aceptamos por coherencia que un efecto sustancial de reconocer un derecho esencial de la persona humana es su inclusión permanente en el ordenamiento jurídico, con notas de perennidad e intangibilidad en cuanto tal, no cabe menos que detenerse a considerar cuáles son las obligaciones que se desprenden de la sujeción a la justicia constitucional para los órganos legislativos $^{29}$ cuando de derechos fundamentales se trata. Cea ha señalado que en un Estado Constitucional de Derecho ha de existir "una disposición, constante y sin reticencias, de todos los órganos jurídicos y políticos competentes para honrar las sentencias del Tribunal y hacerlas obedecer si fuere necesario" 30 .

A este respecto es muy importante destacar que el artículo 31 del proyecto de Ley Orgánica Constitucional del Tribunal Constitucional, en discusión legislativa durante el año 2006, señalaba en uno de sus incisos que "Los órganos del Estado están obligados al cumplimiento de lo que el Tribunal resuelva". Posteriormente, la Cámara de Diputados estimó redundante la frase y consideró que la fuerza vinculante de sus sentencias no requería ser explicitada en su ley orgánica ${ }^{31}$. A pesar de no haber quedado incorporada de manera expresa, entendemos que la norma señalada sí es parte de nuestro ordenamiento. Ello se desprende de la historia fidedigna de la ley, pero también de la aplicación de los principios básicos de un Estado de Derecho, particularmente de los principios de supremacía constitucional, contenido en el artículo $6^{\circ}$ de la Carta Fundamental, de igualdad ante la ley, garanti-

29 Sobre el particular, especialmente interesante es el estudio de PEÑa (2006).

30 CEA (2008) p. 170.

31 Nogueira (2006b) p. 105. zado en el artículo 19 No 2, y de certeza y seguridad jurídica que reclama la necesaria estabilidad político jurídica en cualquier sociedad.

De este modo, la interpretación efectuada por el Tribunal Constitucional sobre el sentido y alcance de los preceptos constitucionales, dentro del marco institucional que le es propio, debe considerarse parte integrante de la propia Constitución y, por ende, vincula directa y obligatoriamente a todos los órganos del Estado, conforme al inciso segundo de su artículo $6^{\circ} \mathrm{y}$, además, cuando aquellas interpretaciones recaigan en materia de los derechos esenciales que emanan de la naturaleza humana, constituye un límite a la soberanía y, por tanto, al ejercicio de la potestad de esos mismos órganos. Con razón, entonces, la Magistratura Constitucional chilena ha señalado al respecto: "Resulta imperativo recordar lo preceptuado en el artículo $5^{\circ}$, inciso $2^{\circ}$ de la Constitución, porque allí se impone a todos los órganos estatales, comenzando con el legislador, la obligación de respetar y promover el ejercicio de los derechos fundamentales (...) Pues bien, la sujeción de tales órganos a lo ordenado en aquel precepto es aún más categórica e ineludible si se tiene presente que se trata de una base del sistema institucional, cuyo vigor normativo se irradia, de manera directa e inmediata, a la Carta Fundamental entera y a toda la legislación complementaria" 32 . En el sustrato de esta preceptiva constitucional está la idea, fuertemente arraigada en el constitucionalismo tradicional, que las constituciones son, ante todo, instrumentos del derecho para contener el poder del Estado, por eso, incluso más importante que el reconocimiento o afirmación explícita de un cierto catálogo de derechos, es que consideren las instituciones que permitan limitar el ejercicio del poder de los órganos del Estado. Si la contención de los poderes estatales se logra en una medida razonable, ello redundará en la protección de los derechos de las personas y en el afianzamiento de las libertades públicas subsiguientes. Por

\footnotetext{
32 Véase el Considerando Decimotercero de la Sentencia rol No 437 de 2005 del Tribunal Constitucional chileno.
} 
otra parte, dicha norma recoge el desarrollo político y jurídico que ha venido experimentando en las últimas décadas, paulatina pero sostenidamente, el sistema internacional de los derechos humanos.

\section{A PROPÓSITO DE UNA RECIENTE LEY}

Esta discusión no podría ser más relevante dada la reciente aprobación por el Congreso Nacional de la Ley $N^{\circ} 20.418$, de 2010, sobre información, orientación y prestaciones en materia de regulación de la fertilidad ${ }^{33}$, toda vez que su vigencia implica la supresión, por parte de los poderes colegisladores, de los efectos de la decisión vinculante del Tribunal Constitucional chileno, establecida en su Sentencia rol No 740 de 2008 , en lo relativo a la adecuada protección que debe dispensarse al derecho a la vida del que está por nacer, derecho reconocido y garantizado en el artículo $19^{\circ}$ número $1^{\circ}$ de nuestra Constitución.

Desde luego, cabe poner en duda la pertinencia de que, mediante la aprobación de dicha ley, los poderes colegisladores hayan pasado por alto lo decidido en una sentencia constitucional que cuenta con fuerza de cosa juzgada material, produce efectos erga omnes y respecto de la cual no procede recurso alguno, por aplicación de los artículos $7^{\circ}$ y $94^{\circ}$ de la Carta Magna, al menos en lo que dice relación con la administración de los métodos de anticoncepción hormonal de emergencia ya proscritos por considerárselos inconstitucionales. Pero, adicionalmente, y tal vez de mayor trascendencia aún, estando los poderes colegisladores obligados por el principio de supremacía constitucional consagrado en el artículo $6^{\circ}$ inciso 1 de la Carta Fundamental, resulta del todo improcedente, a nuestro juicio, que dichos poderes -en el ejercicio de la potestad libre de la que gozan para configurar el ordenamiento jurídico, según su legítima voluntad y el juego de mayorías y minorías- dejen de considerar los precedentes establecidos por nuestra Magistratura Constitucional en su tarea de interpretación jurídica, realizada en su

\footnotetext{
33 Para consultar sobre su tramitación puede verse
} el Boletín N 6582-11 del Congreso Nacional. rol institucional de exégeta final de la Constitución y, por la vía de aprobar una ley, en los hechos socaven los fundamentos y contenidos de una decisión de la justicia constitucional, lo cual pugna, además, con lo dispuesto por el artículo $76^{\circ}$ de la Norma Fundamental. Tratándose dicha sentencia de un pronunciamiento sobre derechos fundamentales, es pertinente enfatizar aquí que para dichos poderes colegisladores, al igual que para el Estado en su conjunto, es imperativo el dogma constitucional que les exige estar al servicio de la persona y les impone como finalidad promover el bien común con pleno respeto a los derechos y garantías constitucionales ${ }^{34}$.

Precisemos que el fallo de inconstitucionalidad dictado por el Tribunal Constitucional, a juicio nuestro, radicó en un vicio de aquellos que Zapata califica como "de contenido de contradicción virtual o de efecto incompatible", esto es, de vicios en los que para cuantificar si se produce o no una vulneración constitucional "resulta necesario indagar respecto a los potenciales efectos o consecuencias" $35 \mathrm{de}$ la norma en análisis. En este caso, por supuesto, los potenciales efectos o consecuencias de la norma en análisis son, a su vez, los potenciales efectos de la ingesta de la 'píldora del día después'. Esta cuestión de hecho fue la materia principal debatida ante el Tribunal Constitucional: la falta de certeza científica respecto de lo nocivo o inocuo de sus efectos es, precisamente, lo que funda la duda razonable que justifica la declaración de inconstitucionali$\mathrm{dad}^{36}$.

Cabe preguntarse entonces ¿cuál es la ratio decidendi de la sentencia? Evidentemente ella no puede radicar en los virtuales efectos de los métodos anticonceptivos hormonales de emergencia, pues siendo ellos una cuestión de hecho, no puede renunciarse a su eventual revisión. Tampoco radica, a nuestro entender, en la aplicación al caso de criterios hermenéuticos

\footnotetext{
${ }^{34}$ Sobre el particular pueden revisarse SILVA y SILVA (1995) y SOTO (1995).

35 ZAPATA (2008) p. 314.

36 Véanse los considerandos Vigésimo Primero y Trigésimo Noveno de la Sentencia rol N $\mathrm{N}^{\circ} 740$ de 2008 del Tribunal Constitucional chileno.
} 
desarrollados por la teoría de los derechos fundamentales, como el principio pro homine ${ }^{37}$ a que recurre el fallo, pues dicha aplicación será necesariamente una materia prudencial y de aplicación casuística, aunque el recurso a dicho principio ha quedado legitimado en su eficacia normativa hacia el futuro. Más bien la ratio decidendi del fallo reside en el reconocimiento de la titularidad del derecho a la vida del que está por nacer desde el momento de su concepción y la necesidad que surge de inmediato de protegerlo de amenazas plausibles que, aunque sean circunstanciales, la ciencia aún no puede descartar $y$, por ende, mantienen su efecto virtualmente incompatible con la Carta Fundamental.

Dicho esto, surge una nueva cuestión. ¿Puede una ley sanear el vicio de inconstitucionalidad de que adolece la distribución de los métodos hormonales de anticoncepción de emergencia? Esta pregunta nos remite nuevamente al contenido material del fallo: el pronunciamiento del Tribunal Constitucional es de fondo, es decir, versó sobre los métodos mismos que podían resultar lesivos al derecho fundamental a la vida y, de la constatación de que era plausible, razonablemente, que esos métodos sí pudieran conculcar ese derecho coligió la inconstitucionalidad del Decreto que permitía su distribución y lo arrojó de nuestro ordenamiento jurídico. Pues bien, no se ve cómo una determinada cosa que se considera que puede ser o resultar lesiva para un derecho pueda dejar de serlo por el solo hecho de ser sometida a aprobación legislativa. ¿O acaso puede la consagración legal de una norma despejar la duda razonable que fundó la declaración de inconstitucionalidad? Obviamente que no. El vicio que afectó a parte del Decreto Supremo $N^{\circ} 48$, del Ministerio de Salud, de 2007, persiste en la ley recientemente aprobada y en cualquier otra, sea cual sea su rango, que persevere en promover los métodos de an-

$\overline{37 \text { "Este principio indica que el intérprete y el opera- }}$ dor han de buscar y aplicar la norma que en cada caso resulte más favorable para la persona humana, para su libertad y sus derechos, cualquiera sea la fuente que suministre esa norma-internacional o interna-" (BIDART, 2000, p. 13). ticoncepción hormonal de emergencia en cuanto estos ya fueron considerados inconstitucionales por el Tribunal Constitucional.

Por lo tanto, a los poderes colegisladores les está vedado reproducir el contenido material o jurídico de un acto que fue declarado inconstitucional por razones de fondo, mientras subsistan en la Constitución las mismas normas que sirvieron de fundamento a la declaración de inconstitucionalidad. Con la consideración adicional de que, en este caso, los enunciados normativos que fundaron el vicio de constitucionalidad se refieren a derechos esenciales y, por ende, no pueden ser eliminados de nuestra Constitución y, aunque lo fueran formalmente, igual seguirían vigentes en carácter de derecho implícito, pero con la misma fuerza vinculante. En efecto, el respeto a las competencias propias de cada órgano del Estado exige que el legislador no pueda invadir las materias que son de competencia de otros de esos órganos, pues ello importaría violentar no solo las reglas de la Carta Fundamental, particularmente su artículo $7^{\circ}$ inciso 2 , sino que además supondría ignorar los valores expresados en ella y que han sido recogidos en la interpretación axiológica que la Magistratura Constitucional chilena ha venido propugnando consistentemente.

Adicionalmente procede preguntarse ¿a $^{a}$ quién le corresponde efectuar una revisión de las circunstancias que sostienen la resolución del conflicto? Consideramos que si el máximo intérprete de la Constitución ya se ha pronunciado sopesando dichas circunstancias, no corresponde a los órganos legislativos cuestionarla sin más, pues ello violentaría los fundamentos mismos del Estado de Derecho en cuanto implicaría la revisión de los fundamentos de su resolución y del contenido de su decisión y, por tanto, pugnaría con la adecuada separación e independencia entre los poderes del Estado y el respeto orgánico que debieran dispensarse los unos a los otros en las esferas de competencia que les son propias $y$, por ende, sería contrario a los artículos $6^{\circ}, 7^{\circ}, 76^{\circ}$ y $94^{\circ}$ de la Constitución. Por supuesto que no puede extremarse lo señalado hasta el punto de plantear un cercenamiento de las atribuciones del órgano legislativo; la irrevocabilidad de la interpretación que se 
ha hecho del derecho fundamental a la vida que planteamos, no estará a salvo de la 'objeción democrática' que frecuentemente se esgrime para impugnar los poderes del Tribunal Constitucional, ni tampoco, por cierto, estará exenta de una importante cuota de judicial activism. Frente a estos cuestionamientos, solo podemos oponer la aplicación de su contrapartida teórica: la aplicación consciente de la doctrina de la judicial restraint.

De este modo, una solución que quiera ser armónica con las bases de la institucionalidad del ordenamiento constitucional y con nuestro Estado de Derecho no podrá más que colegir que sí puede ser objeto de regulación legal la distribución gratuita de la 'píldora del día después'. Sin embargo, solo podrá serlo si existen nuevas circunstancias que ameriten desestimar el fallo pronunciado; en la especie, si surge nueva evidencia que permita al propio Tribunal Constitucional despejar la duda razonable acerca de la existencia de posibles efectos nocivos para el embrión producidos por el 'levonorgestrel' en determinadas dosis. Nueva evidencia que, reiteramos, debiera ser sopesada únicamente por dicha Magistratura y nunca por otros poderes del Estado, pues si estos tuvieran la capacidad de revisar los hechos que dieron sustento a uno de sus fallos entonces simplemente su eficacia se vería conculcada, con la consecuente pérdida para el Estado de Derecho. Apoya esta tesis el criterio básico establecido por la Constitución en la segunda parte del inciso primero de su artículo $76^{\circ}$ -que, no está de más apuntarlo, abre el capítulo dedicado al Poder Judicial- respecto de la independencia de que deben gozar los tribunales establecidos por ley: "Ni el Presidente de la República ni el Congreso pueden, en caso alguno, ejercer funciones judiciales, avocarse causas pendientes, revisar los fundamentos o contenido de sus resoluciones o hacer revivir procesos fenecidos". Si bien esta norma no fue establecida de modo expreso para el Tribunal Constitucional, sí le es aplicable, puesto que deriva de un principio funcional a toda magistratura y, además, es consustancial al Estado de Derecho. Baste para enfatizar el punto anterior, citar la propia jurisprudencia de nuestra Corte Constitucional, que ha señalado:
“(...) en la misma línea estrictamente jurídica que caracteriza a toda sentencia, es preciso recordar que 'los preceptos de esta Constitución obligan tanto a los titulares o integrantes de dichos órganos como a toda persona, institución o grupo' (artículo 6 ${ }^{\circ}$, inciso segundo, de la Constitución). Fluye de lo expuesto que tanto los órganos del Estado, como toda persona, institución o grupo se encuentran en el imperativo de acatar la decisión del Tribunal Constitucional, porque ha ejercido la tarea que el propio Constituyente le ha confiado de velar por la supremacía, sustantiva y formal, de la Carta Fundamental"38.

Aún así, la Ley $\mathrm{N}^{\circ} 20.418$ bien puede pervivir en nuestro ordenamiento jurídico en todo aquello que no pugne expresamente con el fallo. La doctrina de la 'deferencia razonada', por la que tanto celo ha mostrado la Magistratura Constitucional chilena -aunque en vista de la aprobación de esta ley no parece estar recibiendo un trato recíproco- induce a respetar el contenido de la norma en todo cuanto no diga relación con la distribución de la 'píldora del día después'. Así al menos debiera comprenderse la ley sobre información, orientación y prestaciones en materia de regulación de la fertilidad, simplemente porque hasta ahí llegan las potestades de los órganos colegisladores y no más allá.

\section{CONCLUSIÓN}

La interpretación del Tribunal Constitucional, mientras no sea revocada por un nuevo criterio emanado del mismo órgano, es parte de la propia Constitución y está llamada a tener significativa influencia en los órganos del Estado. Los criterios y razonamientos jurídicos centrales que son fundamento directo de la decisión plasmada en una sentencia constitucional tienen fuerza vinculante como precedente y obligan al propio Tribunal Constitucional en sus decisiones futuras, así como al resto de los órganos del Estado, particularmente al Gobier-

38 Véase el Considerando Septuagésimo de la Sentencia rol No 740 de 2008 del Tribunal Constitucional chileno. 
no y al Congreso Nacional. El precedente entrega estabilidad a las razones jurídicas que fundan las decisiones de justicia constitucional y es clave para la certeza jurídica y la previsibilidad de los fallos judiciales, sobre todo cuando se refieren a derechos humanos.

En el caso concreto de la Sentencia constitucional rol No 740 de 2008 , el precedente reside en reconocer al que está por nacer como sujeto titular del derecho a la vida desde el momento mismo de su concepción y la necesidad de protegerlo de potenciales amenazas. Reconocido y fijado el alcance del derecho a la vida de aquel que está por nacer, aun por vía jurisprudencial, ya no cabe la regresión, pues esta constituiría en sí misma una violación al derecho base que se encuentra en la cúspide de la humanidad, con el consiguiente desmoronamiento del andamiaje jurídico sobre el que reposa toda la dogmática de los derechos humanos.

Más aún. Si un derecho fundamental fuera degradado o eliminado del catálogo de derechos reconocidos y asegurados formalmente por la Constitución, por medio de una reforma legislativa, cualquiera sea su rango, este derecho igualmente seguiría obligando a todos los órganos del Estado en carácter de derecho implícito, pues los derechos humanos reconocidos por el Código Político son una barrera infranqueable para los poderes colegisladores. En consecuencia, no corresponde a los órganos con atribuciones legisladoras excusarse en el proceso de formación de la ley para cuestionar una sentencia del Tribunal Constitucional -que goza de cosa juzgada material y que produce efectos erga omnes- ni tampoco para revisar sus fundamentos o contenido. Los poderes colegisladores no pueden sostener en una ley el contenido material de un acto declarado inconstitucional por razones de fondo mientras subsistan las normas que fueron fundamento de su inconstitucionalidad. Con la consideración adicional de que, en este caso, la norma que fundó la inconstitucionalidad versa sobre derechos esenciales y, por ende, no puede ser eliminada de nuestra Constitución y, aunque lo fuera formalmente, igual seguiría vigente en carácter de derecho implícito, pero con la misma fuerza vinculante.

\section{REFERENCIAS}

Alcalde Rodríguez, Enrique (2008): "Relación entre valores y principios generales de derecho en la interpretación constitucional de los derechos fundamentales en Chile", en: Revista Chilena de Derecho, vol. $35 \mathrm{~N}^{\circ} 3$, pp. 463-484.

AlDUNATE LizANA, Eduardo (1993): “Jurisdicción constitucional y cosa juzgada constitucional”, en: Revista Chilena de Derecho, vol. $20 \mathrm{~N}^{\circ} 02$ y 03 , pp. 355-359.

AleXY, Robert (2002): Teoría de los Derechos Fundamentales (Traducción de Ernesto GARZÓn VAldés Madrid, Centro de Estudios Políticos y Constitucionales) 607 pp.

BIDART CAMPOS, Germán (2000): "Las fuentes del derecho constitucional y el principio pro homine", en: BIDART CAMPOS, Germán y GIL DomíngueZ, Andrés (Coord.), El derecho constitucional del siglo XXI: diagnóstico y perspectivas (Buenos Aires, Ediar) pp. 11-22.

BIDART CAMPOS, Germán (1994): La interpretación del sistema de derechos humanos (Buenos Aires, Ediar) 269 pp.

CEA Egaña, José Luis (2008): "Efectos de la declaración de inconstitucionalidad. Dificultades y desafíos", en: Revista Actualidad Jurídica, Año IX No 17, pp. 165-174.

Cea Egaña, José Luis (2002): Derecho Constitucional chileno (Santiago, Editorial Universidad Católica de Chile) tomo I, 405 pp.

CEA EgAÑA, José Luis (1992): "La interpretación axiológica de la Constitución”, en: VV. AA. Interpretación, integración y razonamiento jurídicos (Santiago, Universidad de Chile, Universidad Adolfo Ibáñez y Editorial Jurídica de Chile) pp. 89-97.

Cervati, Angelo Antonio (1991): "El legislador de los derechos fundamentales", en: LÓPEZ PINA, Antonio (ed.), La garantía constitucional de los derechos fundamentales. Alemania, España, Francia e Italia (Madrid, Editorial Complutense) pp. 51-75.

Colombo CAmpBell, Juan (2002a): "Funciones del derecho procesal constitucional", en: Revista Ius et Praxis, Año 8 No 2, pp. 11- 69.

Colombo Campbell, Juan (2002b): "La justicia constitucional", en: Revista de Derecho 
de la Universidad Católica de la Santísima Concepción, $\mathrm{N}^{\circ} 10$, pp. 535- 549.

DíAZ DE VAldÉS JUliÁ, José Manuel (2007): "Algunas preguntas pendientes acerca del control de constitucionalidad de los proyectos de reforma constitucional", en: FERMANDOIS, Arturo (ed.), Sentencias destacadas 2006 (Santiago, Libertad y Desarrollo) pp. 145-176.

DíAZ ReVORIO, Francisco Javier (1997): Valores superiores e interpretación constitucional (Madrid, Centro de Estudios Políticos y Constitucionales) $592 \mathrm{pp}$.

FreiXes SANJUÁn, Teresa y REMOTTI CARBONELL, José Carlos (1992): "Los valores y principios en la interpretación constitucional", en: Revista Española de Derecho Constitucional, Año 12, No 35, pp. 97-109.

GUASTINI, Riccardo (2008): Teoría e ideología de la interpretación constitucional (Traducción de Miguel CARbonell y Pedro SALAZAR, Madrid, Trotta) $102 \mathrm{pp}$.

IgLESIAS VILA, Marisa (2000): "Los conceptos esencialmente controvertidos en la interpretación constitucional", en: Revista virtual Doxa $\mathrm{N}^{\circ} 23$, pp. 77- 104.

NikKen, Pedro (1994): "El Concepto de Derechos Humanos", en: Estudios Básicos de Derechos Humanos, tomo I (San José, Instituto Interamericano de Derechos Humanos) pp. 15-37.

Nogueira AlCalÁ, Humberto (2006a): "La sentencia constitucional en Chile: aspectos fundamentales sobre su fuerza vinculante", en: Revista Estudios Constitucionales de la Universidad de Talca, Año $4 \mathrm{~N}^{\circ} 1$, pp. $97-$ 124.

Nogueira AlCalÁ, Humberto (2006b): Lineamientos de interpretación constitucional y del bloque constitucional de derechos (Santiago, Librotecnia) 413 pp.

PEÑA TORRES, Marisol (2006): "El precedente constitucional emanado del Tribunal Constitucional y su impacto en la función legislativa”, en: Revista Estudios Constitucionales de la Universidad de Talca, Año $4 \mathrm{~N}^{\circ} 1$, pp. 173-184.

Pereira Menaut, Antonio-Carlos (1998): Teoría constitucional (Santiago, Editorial ConoSur) 590 pp.
PICA, Rodrigo (2006): "Acerca de los aspectos generales de la hermenéutica constitucional", en: Revista de Derecho de la Universidad Católica del Norte, Año $13 \mathrm{~N}^{\circ} 1$, pp. 143-169.

PRIETO SANCHÍs, Luis (1987): Ideología e interpretación jurídica (Madrid, Tecnos, Reimp. 1993) 146 pp.

Rubio LlORENTE, Francisco (1993): La forma del poder (Estudios sobre la Constitución) (Madrid, Centro de Estudios Constitucionales) $689 \mathrm{pp}$.

Ruiz Miguel, Alfonso (2000): "Modelo americano y modelo europeo de justicia constitucional", en: Revista virtual Doxa $\mathrm{N}^{\circ} 23$, pp. 145-160.

Silva Bascuñán, Alejandro y Silva GalliNATO, María Pía (1995): "La servicialidad del Estado: sus fundamentos constitucionales", en: Revista de Derecho Público, vol. 57/58, pp. 58-67.

SoTO KLOSS, Eduardo (1995): "La servicialidad del Estado, base esencial de la institucionalidad", en: Revista de Derecho Público, vol. 57/58, pp. 1-13.

ZAPATA LARraín, Patricio (2008): Justicia Constitucional. Teoría y práctica en el derecho chileno y comparado (Santiago, Editorial Jurídica de Chile) 623 pp.

\section{NORMAS CITADAS}

Constitución Política de la República de Chile.

Ley $\mathrm{N}^{\circ} 20.418$, de 2010, sobre información, orientación y prestaciones en materia de regulación de la fertilidad (Boletín 6582-11).

\section{JURISPRUDENCIA CITADA}

Tribunal Constitucional chileno, Sentencia rol No 740 de 18 de abril de 2008, dictada en requerimiento de inconstitucionalidad formulado contra el Decreto Supremo Reglamentario No 48, del Ministerio de Salud, de 3 de febrero de 2007, que aprobó las "Normas Nacionales sobre Regulación de la Fertilidad".

Sentencia rol No 437 de 21 de abril de 2005, dictada en requerimiento de inconstitucionalidad formulado contra el proyecto de 
ley que modifica el Decreto con Fuerza de Ley No 458, de 1975, Ley General de Urbanismo y Construcciones.

Sentencia rol No 325 de 26 de junio de 2001, dictada en requerimiento de inconstitucionalidad formulado en contra del Decreto Supremo No 20, del Ministerio Secretaría General de la Presidencia, de 12 de abril de 2001.

Sentencia rol No 171 de 22 de julio de 1993, dictada en control de constitucionalidad respecto del proyecto de ley que crea Juzgados de Policía Local en las comunas que indica.
Corte Suprema de Justicia de Colombia, Sentencia rol No 51 de 1988.

\section{HISTORIA DE LA LEY}

Mensaje 432-353 del Presidente de la República por el cual inicia un proyecto de ley que modifica la Ley $\mathrm{N}^{\circ}$ 17.997, Orgánica Constitucional del Tribunal Constitucional (Boletín 4059-07).

Actas oficiales de la Comisión de Estudio de la Nueva Constitución Política de la República: sesión $101^{\text {a }}$, de 9 de enero de 1975 . 
